\title{
Chapter 8 \\ Discussion About Sexual Health: Is It Age Inappropriate?
}

In my 5 years of geriatric practice, probably for the first time, I didn't take a patient seriously even though I could see that person was suffering from some agony. It was a busy OPD day in 2012 when our departmental strength of doctors was less, but we used to see an average of 50 patients in a day. I used to devote 15-20 min per patient. Mr. Anil Kumar, a 76-year-old retired financial advisor to the Government of India, visited my OPD with usual complaint of hypertension and one episode of haematuria (i.e. blood in urine). I asked few quick questions regarding geriatric syndromes like fall, depression, frailty, urinary incontinence, dementia, vision and hearing problem, how he spend his leisure time, his passion, etc. I prescribed medicine for his hypertension and asked for prostate-specific antigen and ultrasound of kidney, ureter, bladder and urine culture sensitivity to rule out cancer of prostate or bladder. He was just about to leave my clinic, when he said,

"Doctor I have some major issue other than this".

“Tell me. What happened?" I enquired.

"Actually I am not happy in my life. I am not depressed but not feeling well. I engage myself in various RWA activity, I do a lot of socialization, teach my grand children. Still I am having low mood".

After a pause and looking at my eyes, understanding my attention towards him, he whispered with hesitation.

\subsection{Sexual Health of Older Adults}

"I am not satisfied with my sexual life". He finally mustered.

I burst out laughing, which probably reached other patients who were waiting outside. It was unethical, uncalled for, inappropriate, as a compassionate doctors to my patients. But I don't know why I laughed so much.

My training period, undergraduate and postgraduate, in Geriatric Medicine, had not taught me about eliciting sexual history of an elderly individual, neither were 
there any questions in our examination, as per my knowledge. During my childhood, I never saw my grandparents getting physically close to each other, and they were in their late 60s. I used to sleep with my grandfather, so I always deprived them of staying together. We take it for granted that the ageing is equivalent to the Vedic concept of sannyas, where the old man leaves the family and lives in the jungle and tries to unite with God, and even if they stay in the family, due to hormonal changes and social custom, they will not have any sexual relation with their partners.

"I am sorry, sir" I immediately apologized and asked, "What is your actual problem?"

"Despite of the fact that I have desire and orgasm, there is problem in erection. I love my wife and she also loves me very much. We are married for the last 40 years. My son and daughter are settled abroad and two of us stay in Vasant Kunj, Delhi". He explained.

I tried to review his history again by asking question related to drinking alcohol, which I had missed earlier. He was a chronic alcoholic and had been drinking almost 2 pegs $(60 \mathrm{ml})$ per day of either whisky or vodka for the last 40 years. From the limited knowledge I could gather related to their problem, I knew that the probable cause of erectile dysfunction could be vascular (HTN/DM) or chronic alcoholism. To be very honest, that day I didn't show much interest towards this problem and prescribed an antidepressant tab fluoxetine $20 \mathrm{mg}$ at night and told him in a nonchalant manner, "Stop alcohol, it will be fine, and come back to me with all the investigations I wrote, which is more important for your life". He had a mixed impression about me but of course not a good impression with my other patients. He thought I had ignored his major complaint and didn't even try to explore the problem in detail. Actually I was not knowledgeable enough to do so. I thought I would read about this, but it was not a priority for me. I didn't read about it for a week. He came back with reports which suggested that he was suffering from cancer of prostate stage 1 . I referred him to a urologist and asked to discuss about his problem including his erectile dysfunction with the specialist.

"How is your problem of ED?" I asked him casually, which he didn't like at all and looked at me with a little anxiety and anger.

I told him, "Give some time for the medicine to work and you can try Viagra".

"I have already used it without any benefit; rather it gives me a lot of headache. And your colleague only told me that I should not take it as I have uncontrolled hypertension". He explained.

I was regretting my ignorance. Though I claim myself a lifelong learner, but I didn't read about ED even when I had a whole 1 month.

\subsection{Importance of Detailed History of Both the Partners}

In between I had a discussion with Professor AB Dey about this patient without mentioning his name. I read a review article by Taylor et al. that mentioned various surveys, both postal and face-to-face. The author wanted to dispel the myths of 
asexual old age [1] and described the facts that many elderly people were having an active sex life; some of them had sexual problem and difficulties which they were unable to explain to the healthcare professional, as the professionals usually avoid discussing this problem with older patients, just the way I did.

"Never prescribe Viagra to an old man without getting detailed information about his partner and family". Dr. Dey told me.

"Why, Sir?"

Then he started narrating an incident.

"I had a patient who used to visit me for his various health problems. He was in his 80 s. Once he came to me and explained his desire to have a healthy sexual life with his apparently young wife. He was accompanied by his wife, probably in her 50s. I thought she must be his second wife. After listening to his problem I prescribed him Viagra. In his consecutive visits he was very happy but he did not visit me for another 3 to 4 years. Last year he came with his son and daughter with a gross cachexia (loss of muscle and fat of both upper and lower limb as well as face), so I asked what had happened. His daughter mentioned in his absence that her father is suffering from HIV and chest infection, probably tuberculosis".

Dr. Dey started medication for tuberculosis and tried to explore the cause for HIV infection. Just to make them relax, he asked, "How is your mother doing?"

"To my surprise his daughter told me that her mother had passed away 20 years back, after her dad just retired". Dr. Dey further asked about his second wife. "The daughter was very surprised to hear my question. She responded 'What are you talking, Doctor? He never had a second marriage. He stays alone in Bangalore and working with a publishing house. He has got a full time servant to take care of him. That Lady is very faithful, from our village, takes good care of my father.' I understood his complete history".

So, even at the age of 80 , people can be sexually active, but many a times practical problems force them towards unsafe sexual practice which land them in such problems. HIV acquired in late life is not an uncommon entity. One of the reasons could be as mentioned above.

HIV and AIDS surveillance and control programme is well advanced globally. However the focus of such programme is primarily younger population [2]. Awareness among senior citizens is equally important to avoid such cases. Many a times, lack of partner or partner's poor health could be issues that decrease sexual activity or interest in sex, with increase in age. But sometimes, being unable to suppress it, people land up with this kind of problems.

I'll come back to the story of Mr. Anil Kumar. He consulted the urologist and the urologist worked up for Ca prostrate. He got diagnosed with early stage. The urologist advised not to do anything, just to follow PSA level 3 monthly.

He didn't come to me for 3 months. He tried to meet me at office sometimes, but I ignored him probably considering that he was a hypersexual man or a "sex maniac", which is generally a common perception of general practitioners, from developed nations as well [2].

It was at my Saturday OPD; he said when his turn came, "Doctor, I need some time today, please don't ignore me". 
"Please come, tell me your problem. How is your prostate? How is your blood pressure control?" I asked politely.

I came to know that he had visited almost every week to one or the other doctor in our department and urology department for a solution of ED. I was little receptive on that day considering his anxiousness.

"Tell me in detail". I encouraged him.

"Doctor, don't worry about my hypertension and prostate cancer, which are under control. I am not bothered about that. I am ready to die of prostate cancer, but I want to live a satisfied life. I want to satisfy myself and also my partner". He started explaining.

"Are you depressed? Is the medicine not working?"

"No not at all, doctor. I think I am depressed".

"Are you continuing your alcohol?"

"Yes, depression is stimulating me to take more alcohol".

He was unstoppable, "You know we had so good relationship, I hug her, I kiss her, but when the ultimate time comes I am not able to satisfy her. Our foreplay is adequate, but I fail".

"What about your wife?"

"She is absolutely fine physically. She had dryness in her vagina, for that gynecologist had prescribed using estrogen cream which helped her a lot. But of late she had multiple non-specific physical problems. I think she is not satisfied mentally and sexually".

"Have you discussed about this within your friend circle?"

"No, I did not. You never know who will take advantage of this opportunity".

I was speechless but helpless too. All the necessary investigations, including penile Doppler after infusing injection, showed that the cause of his ED is vascular arterioscleroses, which was unlikely to be cured.

I was flipping through all his reports. This time I confessed, "Sir, I am not an expert in this field and let me do literature survey and read books to understand ED better. Would you mind visiting endocrinology to know whether andropause is causing this?"

"Not a problem doctor, I will do whatever you say".

I knew from my minimal knowledge of andropause that low testosterone could be one of the factors for sexual dysfunction. So I asked for free testosterone level which was not done and also an endocrinology opinion.

He came back after 2 weeks with a hopeless face, "Doctor nobody is bothered, and I believe nobody understands the problem of elderly people, you must read and learn".

"All of you are telling that there is no problem but I am suffering like anything. You people are not empathetic at all. My wife has become irritable. She is helpless too. Now she does not socialize. She is scolding her maid, for no reasons, which she never did. She cannot express her problem with anybody, not even with me". 
I checked his BP, which was normal.

He was on losartan 50. His PSA was 4, which had reduced as compared to previous report showing eight micro-units. So his prostate cancer is not progressing. I had no answer other than to counsel him. I asked, "Can you bring your wife? I can talk to her". Patient's partner should also be included in this discussion as suggested by literature [3].

Penile Doppler study states, "Suboptimal erection partially due to venous incompetence".

I increased the dose of fluoxetine and requested him to stop alcohol again and also referred to psychiatrist for de-addiction. He didn't go, I believe. Before leaving my clinic, he told me, "Can you do something more than this? Please read from literature and let me know. Pleases take my number and give yours. I will not disturb you. If you have any solution please let me know".

The problem of ED is highly prevalent in males, although there is no Indian study, but the US and European community studies had reported a high prevalence for (lack of) "sex drive" (26\%) and erectile dysfunction (26\%) in elderly men. As per the findings of previous studies conducted across the globe, sexual problems were associated with gender, with physical and mental health, demographic factors such as educational attainment, and with happiness in relationship [4-8]. Sexual health in late life is an outcome of a complex interplay of biophysical, psychological and sociocultural factors.

We need a proactive approach to enquire and know more about sexual problems of older adults. I discussed with all my colleagues and nobody asked this question to elderly people. It is a taboo or social inhibition in India. One of my colleagues, who was in his 40s, told me, "You know Dr Prasun, it's not in our culture to ask our older client this kind of personal questions". The patients who attend Geriatric Clinic are at age of our father or grandfather, so there is a natural hesitation in asking this question. Similarly, senior citizens, fathers/grandfathers, never discuss these kinds of issues with children or grandchildren in this country. I don't know how to break this taboo and how to sensitize doctors, especially dealing elderly people, to ask about sexual history proactively.

The likelihood of engaging in partnered sex declines steadily with age. Much of this decline could be due to andropause (hormonal deficiency of male), menopause (hormonal deficiency of female), external ageing changes in the individuals along with unobserved sexual problems like dryness of vagina, increased time of foreplay, etc. Staying in a different room in a joint family could be other confounder. But studies suggested those male and female who are more sexually active, more satisfied with life and less prone to depression [9].

Relationship between the spouses, overall satisfaction in the intimate relationship had a significant impact on the sexual health. So, sexual health is relational and jointly produced rather than simply an outcome for the individual [10]. 


\subsection{Scarcity of Data}

We recently conducted a quick survey, after noticing such problems of elderly, in using a validated questionnaire ADAMS (Androgen deficiency in Aging Males) scale in male and MFSFI (Modified Female Sexual Function Index) in females. A male nurse collected details from male patients and female nurse from female patients after their written consent. The survey was conducted among 50 males and 50 females randomly selected from our Geriatric Medicine OPD. In males, 32 males, that is, $64 \%$, participated in the survey, while the rest $36 \%$ were shy and did not want to discuss their personal issues. As per the ADAMS (Androgen deficiency in Aging Males) scale, of the participated candidates, $56 \%$ were androgen deficit with erectile dysfunction, decreased sexual desire with lack of interest and loss of penile height with a steady increase in age. Among females, most of them, that is, $84 \%$, denied to take part in the survey as they were embarrassed and shy to answer the questions of MFSFI (Modified Female Sexual Function Index). The cause of denial was predominantly due to personal belief and culture. They also felt that the questions were irrelevant for them at that age and of less value or no value. Some patients said that this is not spiritually or religiously right to discuss or to involve in these issues, while in $16 \%$ of 50 women, who participated, felt uncomfortable while having intercourse (unpublished data).

Probably they did not want to discuss, as we received such some comments: "personal matter with juniors/doctors or nurses", "having sex at this stage of life is an offence", "we are religious so it is not possible to discuss" and "it is high time to try to unite with God instead of materialistic life".

It had also been noted among the GPs where they felt disgusted and felt repugnant at the thought of an 85-year-old man asking for Viagra and another saying he had to be careful not to let his Catholic beliefs influence patients, etc.

Mr. Anil Kumar didn't visit me for a long time. He tried with Viagra, alternative medicine and Ayurveda without any improvement.

In our last meeting last year in July 2017, I suggested him to try External Erection-Facilitating Devices Constriction devices, vacuum devices, which also work sometimes. But he refused to use any devices. I tried to explain him about alprostadil intracavernosal injections. In a study of 683 men, 94\% reported having erections suitable after alprostadil injections [11]. If the vasculature within the corpora cavernosa is healthy, intracavernosal injection therapy is almost always effective. The dosage should be adjusted so as to achieve an erection with adequate rigidity for no more than $90 \mathrm{~min}$. Alprostadil doses as high as $40 \mu \mathrm{g}$ can be used. [12]

"I can't take this kind of injection". He rejected the idea out rightly.

He was convinced to use intraurethral prostaglandin E1 pellets which could be useful for 3-6 months. But our urologists from AIIMS refused to prescribe as their experience was not enough.

He understood that there was not much solution to his problem. He was not convinced about his lifestyle modifications. Study suggested lifestyle modifications to improve vascular function (e.g. smoking cessation, maintenance of ideal body 
weight and regular exercise) may prevent or reverse ED. A systematic review and meta-analysis by Silva et al. suggested that physical activity and exercise - particularly aerobic exercise of moderate-to-vigorous intensity - improve patient-reported ED [13].

I could not help Mr. Anil Kumar and left him to live his life with full of agony. But there would always be cases that we won't be able to solve.

\subsection{Anxiety and Depression: A Spoiler Vitality}

Mr. Gaurav was going through a lot of turmoil in his life. He met me in December 2015. He was just 61, had no vascular risk factor like HTN or DM but had history of on and off depression. "This time it is too much. I didn't feel like living anymore", he cried helplessly.

"Why, Mr. Gaurav?" I enquired.

"I feel the world is going to be over. My grocery shop is running well, all of my staff has been working with me for more than 20 years and very faithful. So even if I sit at home it will run very well. But ..." After a pause he continued "You know, I am not happy with my wife too, after menopause she has become very irritable and argues for everything".

I was listening with attention.

"What makes you depressed? Is it the behavior of your wife or something else?" I probed further.

"I don't know, doctor. But one of my friends had cheated me. Jointly we purchased a land and he did a fake registry and now the matter is in the court. He was my friend for the last 40 years. How could he do this?"

"Try to let it go. Court will take its own time. You would definitely win if you are right".

"I am trying, but my wife is not helping. There is a constant irritation from her side".

"Is there any other problem between you and your wife?" I don't know why I asked this question. But this time instantly I asked him "Are you people satisfied in your sexual life?"

He was a little surprised as if I had caught him, "We were satisfied but for the last couple of months I am having problem with erection" after a pause, "That night she almost threw me from the bed because of the height of our emotion, I failed. You know, I have lost all my confidence and self-esteem".

It was a clear case of ED due to stress, so I was very comfortable that he will be fine.

I counselled him for almost half an hour about multiple problems and directed him to our clinical psychologist in psychiatry department, Dr. Deepa, who took some sessions with the couple. I started him on escitalopram $5 \mathrm{mg}$. Gaurav came back after 2 months of medication. His wife accompanied him; he was focusing on his business again. He was happy and congratulated me "Doctor, sexuality is a basic 
human need with existence throughout life in one form or another. It affects a significant component of quality of life and life satisfaction in many older individuals. It is not easy to find empathetic physicians and health care professionals who could solve this problem without losing dignity of the older adults".

Few studies like national council on ageing which conducted a poll regarding attributes of people aged over 65 years reported that men have a stronger sexual drive than woman and this gender gap widened with age. Two large studies, one from University of Chicago studied 3000 US adults aged 57 to 85 years and the health in men study on over 3000 Australian men aged between 75 and 95 which tried to define sexual activity with a partner in last 12 months, suggested that it definitely declines with age but $40 \%$ to $54 \%$ men aged 70 to 80 years reported some sexual activity at least two to three times in a month [10].

A survey conducted among Swedish men explored the sexual function across four different domains including desire, erection, orgasm and ejaculatory functions. It was observed that there was a decrease in all these with increasing age. However, $46 \%$ of the oldest men aged between 70 and 80 years reported to have orgasm at least monthly [14].

\subsection{Lack of Awareness About Safe Sex}

There was another patient, Mr. Ram Kumar, who was visiting me for the last couple of years for his multiple minor issues like back pain, knee pain and mild form of anxiety. He was a retired business man who had a retailor business of medicine in Bihar, which was taken over by his son; Mr. Ram Kumar had a passion to travel and had visited most part of this country. Previously he used to travel almost every month with his wife, who was bed bound now due to hip fracture. Recently he came to me with a sore in his private part and multiple blisters, which I diagnosed as herpes. He was hesitant to show it to me but told me that he was worried about a painful lesion in his private part.

He was a well-groomed man who takes regular physiotherapy for his back pain and took good care of his physic and health. We spent a lot of time discussing his problem as I examined the lesion after closing the door. There were multiple vesicular and ulcerative lesions, characteristic of genital herpes simplex virus infection [15].

"I don't know how this happened". He said anxiously.

"Which state did you visit last?" I asked.

"Manipur".

After continual probing, he admitted that he had an unprotected sexual relationship.

He was crying, "What can I do Dr. Chatterjee, for the last 5 years my wife doesn't allow me to do so. In fact she is not in the position to have any physical relations. After all I am a human being. People think that we cannot have the wish for sexual activity, because we are old and we are grandparents. But I have a lot of desire and where could I fulfill". 
I tried to counsel him about love, care and intimate relationship.

"Dr. Chatterjee, you encourage me so much about active ageing. But on the other side, you are discouraging active sex life".

"No, I am not. I am only suggesting you to manage your stress to be more productive".

Further I explained him about safe sex practices and sent him to our STD counselor.

It was a difficult question and situation that could occur to any older adult, where one partner is not fit enough or not available, whereas the other partner is physically active, not so agile with normal testosterone level and still not achieved andropause. Our societal attitude towards ageing population is not so affirmative. People look at this as a stigma or sexual perversion; even I had thought so initially.

But of course, with ageing there is lengthening of excitement, decreased penile rigidity, longer interval for ejaculation, slowing of the sexual response and more rapid detumescence [16].

So ageing adults need reassurance to avoid fear and anxiety.

\subsection{Love Is Beyond Age}

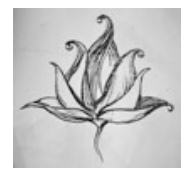

The situation of old-age homes of India is not very encouraging. Predominant elderly individuals staying in old-age homes are waiting to die; there are few people like Meena and Prakash who still have the zeal to live. They were staying in Amar Kutir, a well-known old-age home at Noida. It was just like any other old-age home, with two large halls and two private rooms for couples. In hall there were 20 older men and 19 older females. So there was no scope of romantic liaison between two widowed residents. They had to follow some rules, some ethical concerns, as there were few cases of sexual harassment of especially cognitive impaired residents. So the authority was relatively strict on meeting of people from two different halls. Ms. Meena, a 64-year-old widowed lady without any prodigy, gave everything of her pension to the manager of old-age home and was staying there for her safety and security. She was energetic with full of vitality. She noticed Prakash on her way to the lunch table. She wanted to talk to him, but the authority does not permit that. Somehow, through the attendant she could get the number of Mr. Prakash who was neglected and rejected by family. He had spent his life without doing much. But he was a great cook and was more of a house husband. Mr. Prakash survived on the earning of his wife who was a school teacher. Now his wife, son and daughter-inlaw were staying happily in Kerala in their own house. They shifted Mr. Prakash to an old-age home at another corner of the country so that he could not go back to his 
house. They donated around 3 Lakhs to the old-age home and instructed the authorities not to call them for anything, not even at the occasion of his death. Meena and Prakash became friends. Meena had a fantastic quality of listening and empathizing people. She was the main lady in that hall who would support, cherish, engage the residents and transfer positivity. She used to teach sewing, also used to sing for the residents and spread love for each other. She had revived the gigivisha (will to live) in the resident of the old-age home. Prakash was 60 and Meena was 64 and they fell in love. Ms. Meena requested the authority that they want to live together. But staying together without getting married is a stigma in this country, especially in the old age. It created a scandal and controversy within the campus. We visited the old-age home for health camp. Even local MLA, Mr. Diljith used to visit the centre frequently. Mr. Diljith convinced the authority to organize the marriage of this beautiful bride and groom. The authority allotted a separate room for the couple. They converted their painful lonely old age into a happily married life with a great physical and mental relationship. I could see the positive vibration in that old-age home after the marriage. This couple was working hard to make the old-age home a better place for others.

\subsection{Sexuality Among Cognitively Impaired Gentlemen}

The issues of sexuality are complex, especially in those individuals who has cognitive impairment. Physicians must ask the spouse of demented older adults about their sexual issues as the partner would be embarrassed to reveal sexual difficulties.

Inappropriate sexual behaviour can be seen in person with mild cognitive impairment but more often occurs in persons with moderate-to-severe dementia [14] in the form of unwanted verbal remarks, unwanted touching, sexual aggression and public masturbation - a special care should be taken during appointment of a care provider for dementia patients. I was discussing it with the owner of Tara Devi Lal old-age home, Mr. Agarwal, from Ghaziabad.

"Actually I have a resident with some strange complaint, which I feel as age inappropriate". He hesitantly started.

It was a busy OPD for me, but I still listened to him as we share a good rapport with each other due to my frequent visits to the old-age home. We used to visit the old-age home on regular basis for health check-up camps. But we were not aware about the symptoms of Mr. Keshav, an 80-year-old retired bureaucrat, staying in that old-age home for the past 10 years after the demise of his wife. Off late he had developed some symptoms which Mr. Agarwal was hesitant to explain in front of my colleagues and other patients. So, I took him to a separate room.

"You know Doctor, Keshav Ji was doing well and was managing many of our day to day affairs and executive functioning such as managing the registry of day to day expenses and talking to the funding agency. He has lot of love, care and affection for others. But since last 2 to 3 months we are observing that he is trying to get more close to other inmates, especially ladies. On and off he holds the hands of ladies and 
tries to talk something romantic which is many times inappropriate. But a week ago one of our housekeeping staff noticed that he held somebody near the ladies toilet". After a pause, looking at the ground, he continued anxiously, "I feel he has a lot of sexual desire and excitement. But I don't know how it happened suddenly". He was trying to avoid eye contact with me.

I asked "So what? It is a normal phenomenon".

"No doctor. It is not a normal phenomenon. He was not like that before". Mr. Agarwal insisted.

I told him, "When someone is only loving, caring and affectionate towards others, you can accept that. But you can't accept this behavior?"

"Of course not! Such kind of behavior is not allowed as it would disturb the harmony of the institute and we are not oriented with such issues".

I called Mr. Keshav to have a discussion and told Mr. Aggarwal to go outside. I noticed that he was anxious.

I told "Sir, please don't worry. I would just be asking you some personal questions, if you permit me to do so. This discussion is going to be very confidential and will not be shared even with the owner of the old age home".

"No, Doctor. You don't know. These people are very rude. They are trying to tarnish my image. I love most of the residents". Being an intelligent person, he understood my question; before I could ask anything, he told me, "I did not do anything. I just hold the hands of an old lady to help her to reach the toilet. Then they started abusing me and talked to me in an abusive language as if I have done some criminal offence. Is it not normal to have emotional outburst at the age of 80 ?"

"Of course, sir, it is normal. Our society has some restriction. May be that is the reason your owner was a little hesitant to allow you to do so. Do you have any problem in staying there?" I further asked.

"No, not at all".

I came to know he did not have any other major issues other than well-controlled hypertension and diabetes.

"Fine doctor, now on I will make sure that my behaviour would not disturb the old age home people".

But unfortunately, Mr. Keshav was not fine. He tried to force another lady for some sexual favours. He was beaten up by the employees very badly and got admitted to our department. His hypersexual behaviour had aggravated, and he was blabbering and was very restless to go back to the old-age home. He also tried to hold hand of one of our nursing staffs for no reasons. After stabilizing him with antipsychotics in consultation with a psychiatrist, we did a comprehensive geriatric assessment of Mr. Keshav which showed that he was suffering from cognitive impairment, which precipitated with this kind of behaviour. MRI scan showed there was a small tumour in the frontal lobe which we removed through neurosurgery.

Old-age home residents, especially who are more prone for cognitive impairment and behavioural issues, must be evaluated for their cognitive status. Instead of stamping and labelling them as hypersexual and misbehaving person, the clinician must assess them in a delicate way, and the evaluation must include cognitive assessment and psychiatric assessment, especially mood. 


\subsubsection{Andropause: Judicious Management}

I have seen educated patients approaching me for some very specific problems, like our next story.

I received a mail from Mr. Kabinder stating, "Dear, Dr. Prasun, I heard your speech, in one of your health awareness talks at Safdarjung Enclave. It was very impressive. I am 75 year old man running my consultancy business for new start up after my retirement from IIT. But as you tried to explain frailty, I had some nonspecific symptoms which are bothering me that includes overall slowness both physical as well as mental and mild form of anxiety and depression, needs further discussion face to face. I would like to have an appointment with you, not at your clinic but in your office with some quality time".

I called him on one Saturday to my office.

"Doctor, I have low muscle mass and physical function in spite of a healthy diet for the last couple of months. As you mentioned in your speech, I take two egg whites every day, with sea fish, adequate milk, I do regular walking and try to learn new skills, learning piano, I am writing a non-fiction novel which will be released next year January". He started explaining his daily life.

After a pause "But I am more fatigued and irritable. I feel that my visual memory is declining slowly, as per check up in a private hospital my heart, my lung and everything else is fine. Doctor, I have only one bad habit. I am a smoker for the past 40 years and take almost 20 cigarettes per day. Whole day I feel sleepy but I don't get good sleep in the night".

"Sir! Are you following the sleep hygiene cycle as I discussed in my speech?" I asked.

"Sorry, probably I missed that session. But this is also seen in most of my peer group and I thought it is my ageing changes".

"Do you drink coffee in the evenings?"

"Yes, on regular basis".

"Coffee has a diuretic property, i.e. it forces urine accumulation and that could be the reason that you wake up in the night repeatedly".

Sleep problem is a common issue in late life, due to change in the circadian rhythm. People, especially aged over 80, empty their bladder maximally in the night-time. Further, every time when they get up, they drink some amount of water, which again initiate a cascade of drinking water and peeing. So I recommended him to do some stress relieving exercise, to stop coffee in the evening and to walk in the evening after the sun sets. It stimulates the release endorphin hormone which helps in sleeping [17].

I asked him to show me his reports. I found only a little bit of derangement in cholesterol level. LDL was 158, slightly higher than the normal. Comprehensive geriatric assessment showed almost normal in all the domains, including cognition. His muscle was weak as assessed by our physiotherapist. But his gait speed $(0.8 \mathrm{~m} / \mathrm{s})$ as per Indian standards and grip strength $(18 \mathrm{~kg})$ was normal. I wrote some blood tests and bone tests. 
He came back to me after a few days. As I presumed he was suffering from testosterone deficiency. The total testosterone of 105 and free testosterone was 20 picogram $/ \mathrm{ml}$. Starting testosterone therapy needs detailed interaction and discussion with the patient. As already mentioned, Mr. Kabinder was a learned patient who did a lot of Internet search before he came to me. He told me, "Doctor, is this called andropause? I am suffering from testosterone deficiency".

I was listening. He continued. "I searched on net that testosterone has some good and some bad effect". After a pause, "Oh! During my last visit I forgot to tell you that I am having diminished libido. As per your discussion I understood that it is probably due to frailty. Do you feel that frailty is also due to the low testosterone level?"

He had so many queries and some of them were difficult to answer. But I had a very minimal definite answer. So, I tried to explain to him as much the evidencebased literature suggested.

"Yes, of course! It is possible that the low testosterone could be the cause of libido, but we need to exclude other causes. It causes reduction in muscle mass, low mineral density and poor concentration and memory. But I am not sure how it will improve with therapy and we always have to weigh the effect and side effect along with due consideration to the morbidity profile, geriatric syndrome and functionality. Study suggested that testosterone will slow down bone degradation. But I am not sure how much improvement we can see in bone mineral density" [16].

There are multiple studies in which muscle mass had been evaluated during androgen therapy; changes in lean body mass predominantly muscle mass have occurred consistently [18]. But whether it helped in improving the strength of the muscle was still a controversial topic and doubtful. Few studies suggested that testosterone therapy in conjugation with functional strength training might prove beneficial, but data is still inadequate [16].

"What do you mean?" he enquired.

"Let me explain to you like this. Sarcopenia is basically a loss of muscle mass with age leading to decreased muscle strength and decline in physical function which is happening with you". Showing his thigh muscle I told him, "You can see that your muscle mass and strength, both are reduced and you also mentioned that you have overall decline in physical function".

"Doctor, do you feel androgen therapy would improve my libido after this? And my mood would also be better?"

"I am not sure, Sir. But there are a few hypotheses that testosterone would improve your libido status".

"What about my cognition? After your counseling I thought I am doing better. But still a little slower".

"There are not many studies on this, but I hope that your cognitive status would improve after treating with testosterone".

In the longitudinal study of ageing, high baseline free testosterone index is correlated with better score on visual and verbal memory at baseline and slower decline of visual memory after 10 years of follow-up. But no consistent effect of testosterone replacement has been observed in older men with dementia [16]. 
"Doctor, what about the side effects?"

"Sir, there are side effect of testosterone replacement. But let us try for shortterm therapy followed by assessment of improvement of your symptoms. There would be a few side effects, such as leg edema. Your hemoglobin may increase little bit, tenderness in your breast and it has not been proven but few studies suggest that exacerbation of BPH may happen but good thing is that your premorbid status is very good and you don't have any cardiac issue yet. The only matter of concern is that you are a smoker".

"No, Doctor. I stopped it after listening to your talk".

"Are you an alcoholic?"

"I used to be".

"So, unlikely to have liver toxicity, I believe".

"I saw in Internet that there may be some problem of heart attack or stroke. I also read that there are a lot of side effects of testosterone replacement".

"Yes, Sir. It has. It increases the thickness of the blood by increasing the Haematocrit level; there is chance of DVT (blood clot in leg vein) and stroke in brain or heart". But I assured him to relieve his anxiety, "Somebody who is as mobile like you and doing regular exercise is unlikely to have these side effects".

"Ok tell me, which preparation should I go for?"

I gave him a leaflet where there was different testosterone preparation was mentioned (Table 8.1).

I did explain to him the advantages of various preparations.

I told him, "Preferably you should start with injectable because you have very low testosterone level but it may have a problem of possible discomfort at the injection site and there may be some variation of your testosterone level over single dosing period. We will be giving injection 2-3 week's dose regime which have supra-physiological testosterone level. There is a problem also that there may be significant increase in the hormone level and in between there may be some dip so may have return of the symptoms. But still I believe that you should start with these to achieve the required level and we will follow your blood level of testosterone and estradiol and we will look for the symptoms weekly. Once we achieve the near normal blood level of testosterone we may go for testosterone gel preparation. I am not sure whether it is available in India".

"No problem. My daughter is in the US, so I can get it from there".

"Gel is easy to apply. There is no physiological fluctuation of testosterone level. So, once we switch to gel we need not repeat the blood test frequently".

Various testosterone preparations especially the injectable form have been rather misused many a times. But under diagnosis of testosterone deficiency is a wellknown fact, especially in the very elderly.

Mr. Kabinder was doing well with the testosterone replacement. Studies suggested that an individual with testosterone deficiency having symptoms referred to frailty, sarcopenia, decreased libido or cognitive impairment should be replaced.

Mr. Vijay, an 85-year-old retired politician, had excelled in his overall lifestyle, small eater, reluctant to do exercise but cognitively very active till he was 84 years, but he had gradually developed slowness in his gait movement and cognition with 
Table 8.1 Testosterone preparations for management of ED

\begin{tabular}{|c|c|c|c|}
\hline Preparation & $\begin{array}{l}\text { Recommended initial } \\
\text { regimen }\end{array}$ & Advantages & Disadvantages \\
\hline \multicolumn{4}{|l|}{ Oral } \\
\hline \multirow[t]{3}{*}{17 Alkalated testosterone } & \multirow[t]{3}{*}{ Not recommended } & $\begin{array}{l}\text { Reliable } \\
\text { delivery }\end{array}$ & \\
\hline & & $\begin{array}{l}\text { Good dosing } \\
\text { flexibility }\end{array}$ & \\
\hline & & Low cost & \\
\hline \multicolumn{4}{|l|}{ Injections } \\
\hline \multirow[t]{5}{*}{$\begin{array}{l}\text { Testosterone enanthate } \\
\text { cypionate }(100-200 \mathrm{mg} / \mathrm{cc})\end{array}$} & \multirow[t]{5}{*}{$\begin{array}{l}75 \mathrm{mg} \mathrm{IM} / \text { week or } \\
150 \mathrm{mg} \mathrm{IM} / 2 \text { weeks }\end{array}$} & & $\begin{array}{l}\text { Widely variable serum } \\
\text { T levels over dosing } \\
\text { period }\end{array}$ \\
\hline & & & Mood swings \\
\hline & & & $\begin{array}{l}\text { Significant increase in } \\
\text { haemoglobin }\end{array}$ \\
\hline & & & $\begin{array}{l}\text { Increase in serum } \\
\text { oestradiol levels }\end{array}$ \\
\hline & & & Pain at injection site \\
\hline \multirow[t]{3}{*}{ Implantable pellets } & \multirow[t]{3}{*}{$225 \mathrm{mg} / 4-6$ months } & $\begin{array}{l}\text { May last up to } \\
6 \text { months }\end{array}$ & Local site infection \\
\hline & & \multirow{2}{*}{$\begin{array}{l}\text { Steady serum } \\
\text { T levels }\end{array}$} & Extrusion of pellet \\
\hline & & & $\begin{array}{l}\text { Significant increase in } \\
\text { haemoglobin }\end{array}$ \\
\hline \multicolumn{4}{|l|}{ Transdermal patch } \\
\hline \multirow[t]{3}{*}{$(2.5$ or $5 \mathrm{mg})$} & \multirow[t]{3}{*}{ 5- mg patch/day } & $\begin{array}{l}\text { Easy } \\
\text { self- } \\
\text { application }\end{array}$ & $\begin{array}{l}\text { Dermatitis at } \\
\text { application site }\end{array}$ \\
\hline & & \multirow[t]{2}{*}{$\begin{array}{l}\text { Steady serum } \\
\mathrm{T} \text { levels }\end{array}$} & $\begin{array}{l}\text { Limited dosing } \\
\text { adjustment }\end{array}$ \\
\hline & & & $\begin{array}{l}\text { Poor absorption in } \\
\text { some patient }\end{array}$ \\
\hline \multicolumn{4}{|l|}{ Transdermal gel } \\
\hline \multirow{4}{*}{$\begin{array}{l}(2.5 \text { or } 5 \mathrm{~g} \text { packets, } 5 \mathrm{~g} \\
\text { packets, or pump; } 5 \mathrm{~g} \text { gel } \\
\text { delivers } 5 \mathrm{mg} / \text { day })\end{array}$} & \multirow[t]{4}{*}{$5 \mathrm{mg} /$ day } & $\begin{array}{l}\text { Good dosing } \\
\text { flexibility }\end{array}$ & $\begin{array}{l}\text { Occasional skin } \\
\text { irritation }\end{array}$ \\
\hline & & $\begin{array}{l}\text { Easy } \\
\text { self- } \\
\text { application }\end{array}$ & \multirow[t]{3}{*}{$\begin{array}{l}\text { Poor absorption in } \\
\text { some patients }\end{array}$} \\
\hline & & $\begin{array}{l}\text { Steady serum T } \\
\text { levels }\end{array}$ & \\
\hline & & Invisible & \\
\hline
\end{tabular}

Source: Hazzard's Geriatric Medicine and Gerontology, 7e [16] 
muscle weakness. He had other symptoms, as mentioned in the case of Mr. Kabinder. He had bronchial asthma, prostate problem and weakness in his muscle. Neurologist, internist and physical therapist ordered extensive investigations like PET scan of the brain and ultrasound but without any conclusion to explain the symptom. After 4 months of further deterioration, I asked him to test for testosterone level and inflammatory marker to understand sarcopenia. There was a lot of inhibition by Mr. Vijay, even to test androgen level.

Doctors in India prescribe androgen injection to improve generalized weakness in late life. But mostly the decision is subjective and they explain the patient as "last resort to improve vitality". Evidence only supports the role of androgen replacement in case of documented deficiency.

Mr. Vijay had testosterone deficiency later improved with testosterone therapy.

Assessment of testosterone level, total as well free, should be performed. One or two shots of androgen with subjective recommendation by doctor are not beneficial. Proper explanation to the patient about the effect and side effect is equally important. Though it is a magic drug to improve the muscle mass in testosterone deficient subject, multidisciplinary care should not be undermined. Physical activity, muscle strengthening exercise, cognitive therapy and sleep hygiene cycle also have a role to play.

Testosterone, a wonder hormone, if low, could lead to multiple symptoms, the kind Mr. Kabinder had. Testosterone can be found circulating in the blood, bound to two proteins albumin and sex hormone-binding globulin (SHBG). Only 1-2\% free testosterone circulates totally free in plasma tightly bound to SHBG known as bioavailable testosterone. This bioavailable testosterone correlates with parameters like bone mineral density and sexual functions in older men and can also act as a predictor for the development of frailty. Testosterone can be converted to 17-beta-oestradiol by the action of aromatic enzyme. Bioavailable testosterone decline with ageing in many normal men and most of the studies has been conducted in Caucasian, western European, African-American or Asian descent. While age of the patient is a strong predictive factor for low serum testosterone, concomitant diseases like diabetes, liver diseases, depression and metabolic syndrome can be contributing factors. Smoking is also significantly associated with low testosterone level.

Low testosterone level has an impact on late-onset hypogonadism defined with many non-specific symptoms as of Mr. Kabinder related to musculoskeletal, sexual, decreases energy or motivation, depression, poor concentration and sleep disturbance. The International Society recommends total testosterone level as an initial test for hormonal evaluation and a cut of 200 nanograms [16]. ADAMS's questionnaire for Massachusetts male ageing study questionnaire has a high specificity for either the clinical diagnosis or for the monitoring response to therapy.

\subsection{Necessity to Discuss Sexual Health}

Healthcare professionals must discuss the sexual health of elderly clients with them, without overemphasizing sexuality in the ageing process or over-medicalizing the declining sexual function. There has to have a balance between understanding of 
ageing changes in various domains including physical, psychological, functional and social along with the difficulties in personal life related to sexuality.

In a study conducted by Katz and Marshall [19], the authors described sexual decline in older age, which can be categorized as "modifiable para-aging phenomena" instead of thinking it as inevitable consequence of ageing. However the situations are changing as geriatricians, and even the GPs gradually understand the importance of sexual activity to have a healthy and successful ageing. Stress should also be given to screen the patients with chronic disease, patients with vascular comorbidities like diabetes, hypertension, coronary artery disease, etc. and patients on multiple medication, infections, symptoms of lower urinary tract infections, previous strokes and any form of mood disorders such as anxiety and depression. Direct questions about urogenital problems like any atrophy, infections, burning sensation, etc. should be asked to postmenopausal women. Seeking permission before starting any questions or discussions with the patients is always helpful. Gender issue should be taken into consideration while discussing such issues. Special education should be given to all elderly patients about lifestyle modification like smoking, obesity, diabetes control and alcoholism and its future implications and mention to them other than the known complications of heart problem or brain stoke various sexual functioning.

GPs and elderly care physician must explore the problem of sexual dysfunction in an empathetic way; only raising the issues would not be sufficient. Doctor with inadequate knowledge should not refrain from taking expert opinion from urologist, endocrinologist, geriatrician, sexologist and psychologist, if available, to provide relief to the sufferer. But a care plan has to be jotted down. Motivational interview related to diseases in association with unprotected sexual practice and its future complications must be conveyed specially for the group without any partners but having sexual desire in any form.

\section{References}

1. Taylor, A., \& Gosney, M. A. (2011). Sexuality in older age: Essential considerations for healthcare professionals. Age and Ageing, 40, 538-543.

2. World Health Organization. (2014). National AIDS Programmes. A guide to indicators for monitoring and evaluating national HIV/AIDS prevention programmes for young people. Available at: http://www.who.int/hiv/pub/epidemiology/en/napyoungpeople.pdf. Accessed 25 Feb 2019.

3. Gott, M., \& Hinchliff, S. (2003). Barriers to seeking treatment for sexual problems in primary care: A qualitative study with older people. Family Practice, 20, 690-695.

4. Laumann, E. O., Das, A., \& Waite, L. J. (2008). Sexual dysfunction among older adults: Prevalence and risk factors from a nationally representative U.S. probability sample of men and women 57-85 years of age. The Journal of Sexual Medicine, 5(10), 2300-2311.

5. Clayton, A. H. (2007). Epidemiology and neurobiology of female sexual dysfunction. The Journal of Sexual Medicine, 4(4 suppl), 260-268.

6. Bacon, C. G., Mittleman, M. A., Kawachi, I., Giovannucci, E., Glasser, D. B., \& Rimm, E. B. (2003). Sexual function in men older than 50 years of age: Results from the health professionals follow-up study. Annals of Internal Medicine, 139, 161-168. 
7. Derogates, L. R., \& Burnett, A. L. (2008). The epidemiology of sexual dysfunctions. The Journal of Sexual Medicine, 5, 289-300.

8. Parish, W. L., Laumann, E. O., Pan, S., \& Hao, Y. (2007). Sexual dysfunctions in urban China: A population-based national survey of men and women. The Journal of Sexual Medicine, 4, 1559-1574.

9. Loewenstein, G., Krishnamurti, T., Kopsic, J., \& McDonald, D. (2015). Does increased sexual frequency enhance happiness? Journal of Economic Behavior \& Organization, 116, 206-218.

10. Lindau, S. T., \& Gavrilova, N. (2010). Sex, health, and years of sexually active life gained due to good health: Evidence from two US population based cross sectional surveys of ageing. $B M J, 340, \mathrm{c} 810$.

11. Linet, O. I., \& Ogrinc, F. G. (1996). Efficacy and safety of intracavernosal alprostadil in men with erectile dysfunction. The Alprostadil Study Group. N Engl J Med, 334(14), 873-877.

12. Avasthi, A., Grover, S., \& Sathyanarayana Rao, T. S. (2017). Clinical practice guidelines for management of sexual dysfunction. Indian J Psychiatry, 59(Suppl S1), 91-115.

13. Silva, A. B., Sousa, N., Azevedo, L. F., \& Martins, C. (2017 October). Physical activity and exercise for erectile dysfunction: Systematic review and meta-analysis. British Journal of Sports Medicine, 51(19), 1419-1424.

14. Helgason, A. R., Adolfsson, J., Dickman, P., et al. (1996). Sexual desire, erection, orgasm and ejaculatory functions and their importance to elderly Swedish men: A population based study. Age and Ageing, 25, 285-291.

15. Centers of Disease Control and Prevention. (2015). Diseases characterized by genital, anal, or perianal ulcers sexually transmitted diseases treatment guidelines 2015. Available at: https:// www.cdc.gov/std/treatment/2015/genital-ulcers.htm. Accessed 25 Feb 2019.

16. Halter, J. B., Ouslander, J. G., Studenski, S., High, K. P., Asthana, S., Supiano, M. A., \& Ritchie, C. (Eds.), Hazzard's geriatric medicine and gerontology, 7e. New York: McGraw-Hill.

17. Young, S. N. (2007). How to increase serotonin in the human brain without drugs. Journal of Psychiatry \& Neuroscience, 32(6), 394-399.

18. Bea, J. W., Zhao, Q., Cauley, J. A., et al. (2011). Effect of hormone therapy on lean body mass, falls, and fractures: Six-year results from the women's health initiative hormone trials. Menopause (New York, NY)., 18(1), 44-52.

19. Katz, S., \& Marshall, B. (2003). New sex for old: Lifestyle, consumerism, and the ethics of aging well. Journal of Aging Studies, 17, 3-16.

Open Access This chapter is licensed under the terms of the Creative Commons Attribution 4.0 International License (http://creativecommons.org/licenses/by/4.0/), which permits use, sharing, adaptation, distribution and reproduction in any medium or format, as long as you give appropriate credit to the original author(s) and the source, provide a link to the Creative Commons license and indicate if changes were made.

The images or other third party material in this chapter are included in the chapter's Creative Commons license, unless indicated otherwise in a credit line to the material. If material is not included in the chapter's Creative Commons license and your intended use is not permitted by statutory regulation or exceeds the permitted use, you will need to obtain permission directly from the copyright holder.

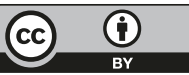

